\title{
The CAUP image database
}

\author{
Jana Veselá*, Pavel ŠKaloud, Pavla Urbánková, Magda ŠKaloudovÁ \& Tomáš \\ KALINA
}

Department of Botany, Faculty of Science, Charles University, Benátská 2, CZ-12801 Prague 2, Czech Republic; *e-mail:vesela6@natur.cuni.cz

\begin{abstract}
The CAUP (Charles University in Prague) image web-database of algae is mostly based on the heritage of the German personalities who were working at the German part of Charles University from the second half of the 19th century to the 1945. Database includes at present 275 images of herbarium specimens, 1,710 images of permanent slides and 1,044 images of living algal strains from CAUP culture collection; in total 1,135 specimens. Nevertheless, many objects in the University collection remained to be non-digitalised and the original species names of objects have been only partially revised.
\end{abstract}

Key words: algae, culture collection, digitalization, herbarium specimens, permanent slides, web-database

\section{Introduction}

The early phycological research in Prague can be dated back to the end of the 19th/ beginning of the 20th century. In 1882, Charles University in Prague was split in the German and Czech University, and phycologists worked in both universities. In the Czech part of Charles University (at the Laboratory of Plant Physiology), the early phycological studies were focused on the isolation and cultivation of cyanobacteria by Václav Uhlír (1892-1915) and Silvestr Prát (1895-1990) (DAY et al. 2004). In the German part of the University in Prague, phycological research was carried out at the Institute of Plant Physiology and at the Botanical Institute. A centre of algal cultivation was established by Professor of Plant Physiology, Ernst Georg Pringsheim (DAY et al. 2004). E.G. Pringsheim (1881-1970) and his collaborator Viktor Czurda (1897-1945) started to isolate and cultivate various strains of algae, mainly coccal and conjugating green algae (Pringsheim 1928). Shortly before World War II, E.G. Pringsheim, who was of Jewish origin, had to emigrate to the United Kingdom, and transferred his strains to the University of Cambridge (DAY et al. 2004; Hermann \& ŠImÚNeK 2010). At the Botanical Institute (now Department of Botany), the phycological group was established by professor of Botany, Adolf Pascher (1881-1945), who investigated flagellate and algal flora from freshwater Central European habitats (FriTsCH 1948). On the basis of comparative morphology and ontogeny observed in the live field material he described many species and genera new to science (Mollenhauer 2001). A. Pascher sympathised with national socialism (Nazi ideology) and the truth about the end of his life remained unclear (Mollenhauer 2001). After World War II, the German University was abolished, whereas the Czech part of the University was reestablished as Charles University (BĚLINA et al. 1998). Because of the lack of financial support in the Czech part of the University during World War II, the collection of algal objects nowadays deposited at Department of Botany mainly originates from the work of early phycologists from the German part of the University. The oldest objects were dated to the second half of the 19th century.

\section{Material and Methods}

Objects for digitalization were selected on the basis of their historical value, taxonomic importance and quality of preservation. Micrographs were taken using an Olympus BX51 with digital camera Olympus E30. Higher resolution of the microscope was acquired by Nomarski DIC optics, U-CA magnification changer and darkfield. Herbarium specimens were digitalised using digital camera Canon D450 and a scanner Canon 
8800F. Original pictures were saved on hard disk and database images were edited in Photoshop CS3 and in XnView 1.96. The maximum size of herbarium specimen images were set to $9000 \times 9000$ pixels, images of permanent slides to $925 \times 694$ pixels and culture collection images to $1000 \times 750$ pixels. At the edge of the images the scale bars and water marks were added. Diatoms with complex, three-dimensional shape were photographed at different focuses and then merged in one image (QuickPhoto Camera 2.3 using the Deep Focus 3.0 module; Fig. 1). Websites were made in a content management platform, Drupal 6.

\section{Objects digitalized in the CAUP image database}

The collection is composed of three types of objects: living algal cultures from the Culture Collection of Algae of Charles University in Prague (CAUP), permanent slides of fixed algae, and herbarium specimens of macroalgae.

The CAUP Culture Collection was established by Bohuslav Fott (1908-1976) in 1961. The collection originated by merging a large number of green algal and heterokont cultures isolated by B. Fott with part of the former E.G. Pringsheim's algal culture collection (almost 20 strains). During the curatorship of Marcela Punčochářová, the algal collection was continuously extended, particularly by the green coccal algae. Presently, the culture collection holds about 200 strains of algae and cyanobacteria, from which 144 are now digitalized.

Permanent slides were either acquired from commercial companies or made by phycologists (Fig. 2). They were prepared by using various mounting and refractive chemical or natural substances and many of the preparation techniques were probably forgotten. Slides of green algae were made mostly by Pfeiffer von Wellheim and J. Lütkemüller. Diatom slides with one species oriented in the centre or with the whole diatom assemblages from diverse places in the world were prepared by commercial companies (e.g., J.D. Möller) or by scientists (e.g., F. Sigmund).

Finally, herbarium specimens of seaweeds were obtained from Titius from Triest or F.M. von Kirchsberg. Although marine phycology was not the main object of research at Charles University. However, excursions in the Mediterranean were undertaken since part of the Adriatic Sea was the constituent of Austria-Hungary.

\section{Browsing of images}

The CAUP (Charles University in Prague) image database is available on the internet at http:// botany.natur.cuni.cz/algo/database.Presently, the database contains 3,029 images of algae; 1,044 images of living cultures (mostly green algae), 1,710 images of permanent slides (mostly diatoms) and 275 images of herbarium specimens (mostly seaweeds); in total 1,135 specimens. Browsing of taxa is possible through three types of navigation in the main menu (Fig. 3). First three links (Culture Collection, Permanent Slides, Herbarium Specimens) enable to view alphabetic list of species within the one type of objects ordered in higher taxonomic categories (phylum and class). Fourth link (Alphabetic Species List) show complete taxa list with the information about the type of object. Using the last main menu link (Search Taxon) it is possible to find words used on the taxon websites, e.g. the original old names or keywords. The codes behind the species names designate the collection code. Pages of individual taxa have small top and bottom navigation

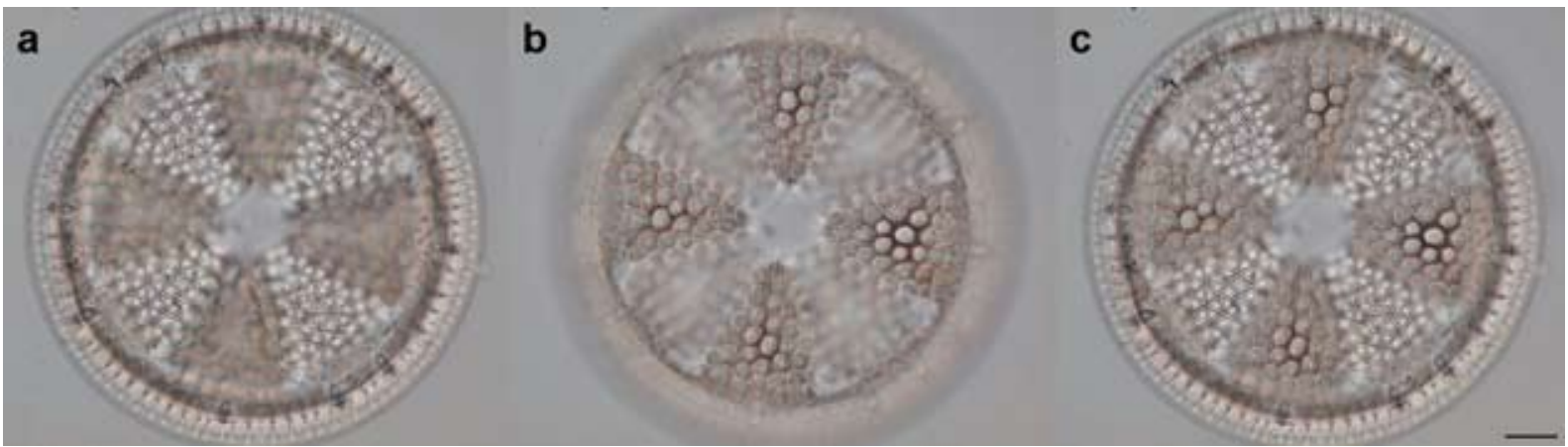

Fig. 1. The First two diatom images $(a, b)$ obtained at different focus were used for the composition of the third image (c). Scale bar $10 \mu \mathrm{m}$. 
(Fig. 3). The top navigation shows hierarchy within the websites; the bottom navigation can be used for browsing of next or previous taxa page (left or right taxon name) and to move to higher category of hierarchy (text Up). The secondary navigation menu refers to the informative pages about the database (e.g., References, Citing \& Founding) and the footer small links redirect to the institutional
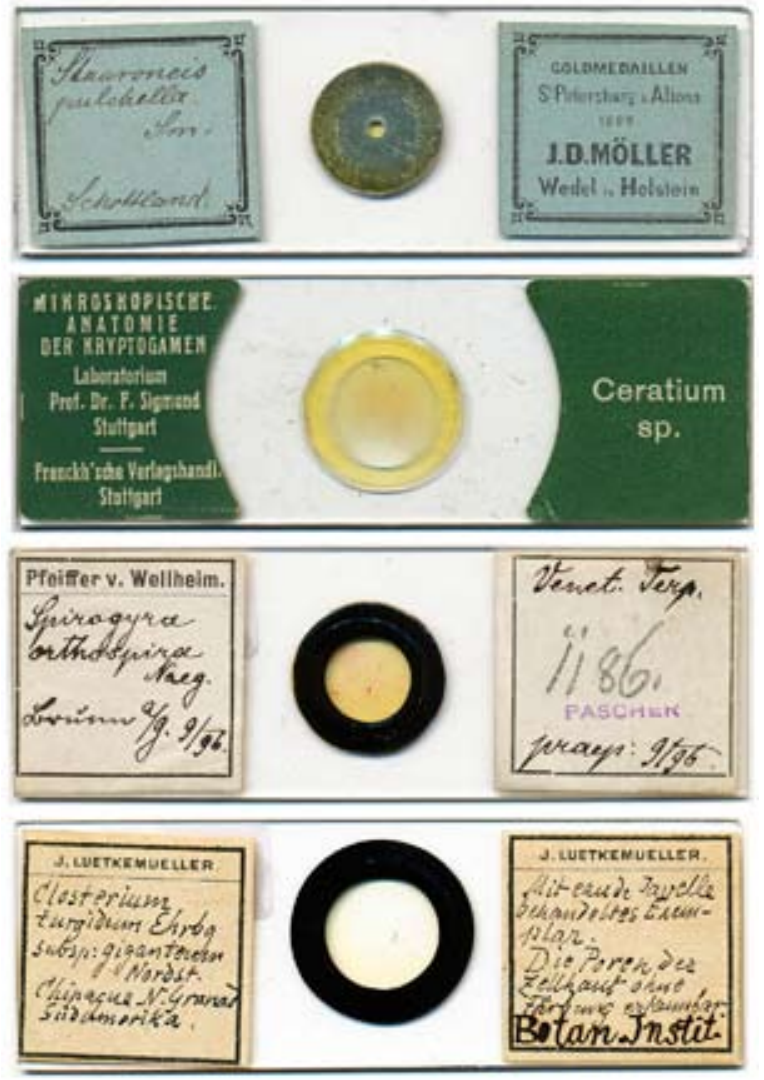

Fig. 2. Photographs of several types of permanent slides deposited in the CAUP collection.

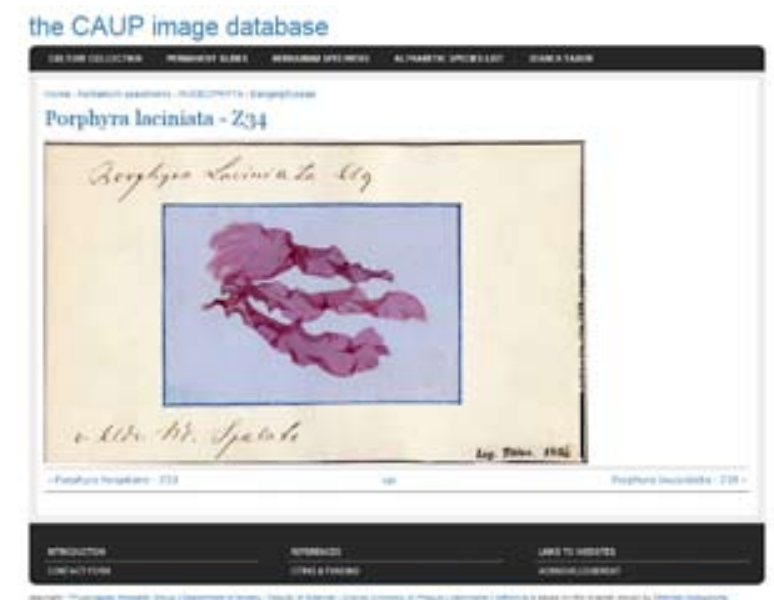

Fig. 3. One of the herbarium specimen page of the CAUP image database. pages. The use of images is subjected to copyright law worldwide and permission should be given by copyright owners (link Contact Form).

\section{Possibilities and limitations of the database}

The CAUP image database follows the aims of other internet databases created by scientific institutions (e.g., AlgaeBase - National University ofIreland, Catalogue ofDiatom Names-California Academy of Science, Diatom Image Database - Royal Botanic Garden Edinburgh). Databases publish for example information important for taxonomic revisions and for describing new species.

In the CAUP image database the original species names (mostly according to names of F. Hustedt, F.M. Kützing and L. Rabenhorst) were preserved and in many cases new valid names were added to the original names. However, considerable amount of objects remained to be revised. Some of the diatom genera in the CAUP image database mentioned Round et al. (1990) as genera which status should be reinvestigated. It is not possible to find out if some of the objects are the type specimens because documentation from German University was lost or destroyed.

A large number of permanent slides that contained diatom assemblages taken from various habitats and geographical areas (e.g., Africa, Austria, Brazil, Japan, Sweden, the United States of America) are deposited in the CAUP collection, as well. These slides have considerable value in studies regarding distribution, diversity and ecology.

The CAUP collection gives the possibility to study the specimens only at the Department of Botany (Charles University in Prague).

Future prospects of the database are: (i) to ask more specialists for help with the revision of names; (ii) to update the database by internet users; and (iii) to enlarge the database with new images of objects which have not been digitalized.

\section{Acknowledgements}

We are grateful to Dr. Fabio Rindi for his help with the determination of seaweeds and to Jan Št'astný for the revision of desmid names. The project was supported by the Higher Education Development Fund No. F4969-2009 and by the Research Project of the Czech Ministry of Education No. 0021620828. 


\section{References}

BĚLINA, P. a kolektiv (1998): Dějiny Prahy II. Od sloučení pražských měst $\mathrm{v}$ roce 1784 do současnosti. [History of Prague II. From merging of Prague towns in 1784 till the present]. - 566pp., Paseka, Praha a Litomyšl.

Day, J.G., LuKavskÝ. J., Friedl, T., Brand, J.J., Campbell, C.N., Lorenz, M. \& Elster, J. (2004): Pringsheim's living legacy: CAUP, CCALA, CCAP, SAG \& UTEX. - Nova Hedwigia 79: 27-37.

FritsCh, F.E. (1948): Profs. Friedrich Oltmanns and Adolf Pascher. - Nature 162: 287-288.

Hermann, T. \& ŠImŮNeK, M. (2010): Univerzita Karlova v Praze, Př́rodovědecká fakulta, 90 let. [Charles University in Prague, Faculty of
Science, 90 years] - 21pp., Přírodovědecká fakulta UK v Praze, Praha.

Mollenhauer, D. (2001): Adolf Pascher(1881-1945) Romantic Phycologist. - Protist 152: 231-238.

Pringsheim, E.G. (1928): Algen-Reinkulturen. - Berichte der Deutschen Botanischen Gesellschaft 46: 216-219.

Round, F. E., Crawford, R. M. \& Mann, D. G. (1990): The diatoms. Biology and morphology of the genera. - 747 pp., Cambridge University Press, Cambridge.

(C) Czech Phycological Society (2011)

Received September 20, 2010

Accepted January 18, 2011 